\title{
3,4-Dihydroxyphenylacetic Acid Measurement
}

National Cancer Institute

\section{Source}

National Cancer Institute. 3,4-Dihydroxyphenylacetic Acid Measurement. NCI Thesaurus.

Code C103345.

The determination of the amount of the 3,4-dihydroxyphenylacetic acid in a sample. 